\title{
Valeria Sperti, La letteratura africana in francese. Dalla Négritude ai giorni nostri
}

\section{Carminella Biondi}

\section{(2) OpenEdition}

1 Journals

\section{Edizione digitale}

URL: http://journals.openedition.org/studifrancesi/1645

DOI: 10.4000/studifrancesi. 1645

ISSN: 2421-5856

\section{Editore}

Rosenberg \& Sellier

\section{Edizione cartacea}

Data di pubblicazione: 1 novembre 2014

Paginazione: 643

ISSN: 0039-2944

\section{Notizia bibliografica digitale}

Carminella Biondi, «Valeria Sperti, La letteratura africana in francese. Dalla Négritude ai giorni nostri », Studi Francesi [Online], 174 (LVIII | III) | 2014, online dal 01 novembre 2014, consultato il 18 septembre 2020. URL : http://journals.openedition.org/studifrancesi/1645 ; DOI : https://doi.org/10.4000/ studifrancesi. 1645

Questo documento è stato generato automaticamente il 18 settembre 2020.

\section{(c) 9 (i) $\Theta$}

Studi Francesi è distribuita con Licenza Creative Commons Attribuzione - Non commerciale - Non opere derivate 4.0 Internazionale. 


\title{
Valeria Sperti, La letteratura africana in francese. Dalla Négritude ai giorni nostri
}

\author{
Carminella Biondi
}

\section{NOTIZIA}

VALERIA SPERTI, La letteratura africana in francese. Dalla Négritude ai giorni nostri, Napoli, Libreria Dante \& Descartes, 2013, pp. 131.

1 Si tratta di un volumetto agile che abbraccia tutta la storia della letteratura africana in lingua francese, destinato ad un pubblico non specialistico, ma ad opera di una studiosa che conosce bene l'argomento, sul quale lavora da anni, e che offre pertanto una summa di ottimo livello su una letteratura non ignorata in Italia, ma che fatica ancora ad uscire dalla cerchia degli specialisti. Il libro è diviso in tre capitoli, seguiti da una cronologia e da una bibliografia. Il primo capitolo, diviso a sua volta in sei paragrafi, si occupa delle «Origini problematiche della scrittura» (pp. 7-22), il secondo, egualmente di sei paragrafi, traccia un panorama generale della «Letteratura africana in lingua francese» (pp. 23-69), il terzo, di quattro paragrafi, di cui due interviste, intitolato «Gli scrittori», si sofferma in maniera puntuale su alcuni esempi significativi (pp. 70-111).

Il primo capitolo si apre con la nascita della scrittura e ne segue lo sviluppo, sulla scia della presenza europea in Africa, un continente considerato dapprima soltanto come una miniera a cui attingere manodopera servile per le colonie americane, poi come territorio di conquista e di colonizzazione, nel quale, per quello che riguarda i paesi conquistati dalla Francia, affonda le sue radici la letteratura oggetto di questo lavoro, e infine il periodo della post-colonizzazione o, talvolta, della neocolonizzazione, che ha visto l'affermarsi di un'importante letteratura nella lingua del colonizzatore. Il capitolo si conclude con due paragrafi dedicati rispettivamente a «Lo statuto dello scrittore e le letterature nazionali», in cui si evidenzia la labilità dei confini fra i vari stati e quindi 
anche la particolarità dello statuto dello scrittore africano e «Il discorso dell'Impero», che studia il complesso rapporto fra letteratura e imperialismo.

Il secondo capitolo, che costituisce il corpo centrale del volume, è una chiara e, pur nella sua brevità, puntuale analisi della letteratura francofona sub-continentale nelle sue diverse articolazioni cronologiche e di genere, partendo dai primi passi, agli inizi del '900, in cui un ruolo importante è stato svolto da amministratori, insegnanti e missionari francesi, per poi soffermarsi sul movimento della Négritude, che segna una cesura nel rapporto con i modelli europei, e crea per la prima volta, grazie al suo teorico, Léopold Sédar Senghor, una poesia di livello mondiale che incentiva in Africa la nascita di una letteratura radicata nella tradizione e attenta alle culture locali. Particolare cura è dedicata da Valeria Sperti al genere narrativo, studiato nella sua evoluzione, dall'epoca coloniale a quella che precede le indipendenze, fino al romanzo postcoloniale, ma non manca una sintesi sullo sviluppo del teatro che, in un paese di tradizione orale, ha avuto un ruolo importante. L'analisi dei fenomeni culturali e delle opere è sempre ben contestualizzata, e permette di seguire in contemporanea l'evoluzione della storia di una parte importante del continente africano, del suo pensiero e della sua letteratura.

4 L'ultimo capitolo si sofferma su due romanzieri, appartenenti a due aree geografiche diverse, il congolese Henri Lopes (nato nel 1937 a Léopoldville) e la senegalese Aminata Sow Fall (nata a Saint-Louis nel 1941) che, pur nelle loro evidenti differenze, riflettono bene i caratteri essenziali e l'evoluzione della narrativa sub-sahariana del Novecento. Un'evoluzione sostanziale e formale, che vede, in estrema sintesi, sostituirsi al problema del rapporto con il colonizzatore quello del rapporto, altrettanto difficile, con il potere autoctono e, sul piano formale, la progressiva liberazione dai condizionamenti del canone europeo. Il capitolo è arricchito da due interviste agli scrittori analizzati. La «Cronologia» che segue permette di situare autori ed opere nel contesto storico, mentre la ricca bibliografia, in cui sono opportunamente indicate, qualora esistano, le traduzioni italiane della produzione letteraria africana in lingua francese aiuta il lettore nel reperimento, non sempre facile, dei testi.

Il lavoro di Valeria Sperti, pur destinato, come si è detto, ad un pubblico non specialistico, costituisce un bilancio critico rigoroso della letteratura sub-continentale africana di lingua francese. 